\title{
Intraoperative glucose variability, but not average glucose concentration, may be a risk factor for acute kidney injury after cardiac surgery: a retrospective study
}

\section{La variabilité glycémique peropératoire, et non la concentration glycémique moyenne, pourrait être un facteur de risque d'insuffisance rénale aiguë après une chirurgie cardiaque: une étude rétrospective}

\author{
Karam Nam, MD · Yunseok Jeon, MD, PhD - Won Ho Kim, MD, PhD · Dhong Eun Jung, MD • \\ Seok Min Kwon, MD • Pyoyoon Kang, MD • Youn Joung Cho, MD • Tae Kyong Kim, MD, PhD (1)
}

Received: 10 July 2018/Revised: 18 January 2019/Accepted: 18 January 2019/Published online: 15 March 2019

(C) Canadian Anesthesiologists' Society 2019

\begin{abstract}
Purpose Altered perioperative glycemic control may contribute to the development of renal dysfunction in cardiac surgery patients. Nevertheless, whether it is intraoperative hyperglycemia or increased glucose variability that affects postoperative outcomes is not yet clear. The aim of this study was to assess the association of intraoperative glucose concentration and variability with acute kidney injury (AKI) after cardiac surgery.
\end{abstract}

Electronic supplementary material The online version of this article (https://doi.org/10.1007/s12630-019-01349-0) contains supplementary material, which is available to authorized users.

K. Nam, MD - Y. Jeon, MD, PhD - W. H. Kim, MD, PhD

D. E. Jung, MD · Y. J. Cho, MD

Department of Anesthesiology and Pain Medicine, Seoul

National University Hospital, Seoul, Korea

S. M. Kwon, MD · P. Kang, MD

Department of Anesthesiology and Pain Medicine, Seoul

National University Hospital, Seoul, Korea

Department of Anesthesiology and Pain Medicine, SMG-SNU Boramae Medical Center, Seoul, Korea

T. K. Kim, MD, PhD ( $\square)$

Department of Anesthesiology and Pain Medicine, Seoul

National University Hospital, Seoul, Korea

e-mail: ktkktk@gmail.com

Department of Anesthesiology and Pain Medicine, SMG-SNU Boramae Medical Center, Seoul National University College of Medicine, Seoul, Korea
Methods We retrospectively reviewed the electronic medical records of 3,598 patients who underwent cardiac surgery between November 1, 2006 to December 31, 2016. The time-weighted average glucose (TWAG) and coefficient of variation of glucose measurements were both used as measures of intraoperative glucose control with multivariable logistic regression to evaluate their relationship to postoperative AKI.

Results The intraoperative glucose coefficient of variation was an independent risk factor for AKI after cardiac surgery (highest quartile odds ratio, 1.38; 95\% confidence interval, 1.09 to $1.75 ; P=0.01)$. Nevertheless, the intraoperative TWAG did not remain in the final multivariable model of postoperative AKI.

Conclusion Intraoperative glucose variability, but not the average glucose concentration itself, may be a risk factor for AKI after cardiac surgery.

Résumé

Objectif Un contrôle glycémique périopératoire déficient pourrait contribuer à l'apparition d'une dysfonction rénale chez les patients de chirurgie cardiaque. Toutefois, nous ne savons pas si c'est une hyperglycémie peropératoire ou l'augmentation de la variabilité glycémique qui affecte les pronostics postopératoires. L'objectif de cette étude était d'évaluer l'association entre la concentration et la variabilité glycémiques peropératoires et l'insuffisance rénale aiguë (IRA) après une chirurgie cardiaque.

Méthode Nous avons rétrospectivement passé en revue les dossiers médicaux électroniques de 3598 patients ayant 
subi une chirurgie cardiaque entre le $1^{\text {er }}$ novembre 2006 et le 31 décembre 2016. La moyenne glycémique pondérée dans le temps et le coefficient de variation des mesures glycémiques ont été utilisés comme mesures de la régulation glycémique peropératoire, et la régression logistique multivariée a été utilisée pour évaluer leur relation à l'IRA postopératoire.

Résultats Le coefficient de variation peropératoire de la glycémie était un facteur de risque indépendant d'IRA après une chirurgie cardiaque (rapport de cotes du quartile le plus élevé, 1,38; intervalle de confiance $95 \%$, 1,09 à 1,75; $P=0,01$ ). Toutefois, la moyenne glycémique peropératoire pondérée dans le temps n'est pas demeurée dans le modèle multivarié final de l'IRA postopératoire.

Conclusion La variabilité peropératoire de la glycémie, et non la concentration glycémique moyenne, pourrait être un facteur de risque d'IRA après une chirurgie cardiaque.

Acute kidney injury (AKI) frequently occurs after cardiac surgery, ${ }^{1}$ and is associated with increased short- and longterm mortality. ${ }^{1,2}$ The development of AKI after cardiac surgery is multifactorial, in which the inflammatory response and ischemia-reperfusion injury play a major role. $^{3,4}$ In particular, cardiac surgery can induce inflammation by provoking hypo-perfusion and subsequent ischemia-reperfusion injury to an end organ such as the kidney. ${ }^{5,6}$ In addition, direct blood contact with the artificial surfaces of the cardiopulmonary bypass (CPB) system triggers a systemic inflammatory response. ${ }^{4}$

Previous studies have focused on glucose concentration alone in terms of association between glycemic control and renal dysfunction in critically ill or cardiac surgery patients. $^{7-10}$ In recent years, not only average blood glucose concentration but also glucose variability has gained attention in glycemic control. Indeed, glycemic fluctuation (or oscillation) was suggested to contribute to the development of diabetic complications through various mechanisms with the inflammatory response, oxidative stress, and subsequent endothelial dysfunction playing key roles. ${ }^{11}$ Increased glucose variability is related to shortterm mortality in critically ill and septic patients. ${ }^{12-14}$ Given the high incidence of postoperative AKI and frequent disturbance of glucose homeostasis during cardiac surgery, ${ }^{15}$ identification of the impact of intraoperative glucose concentration and variability on postoperative AKI is of particular importance. Nevertheless, literature on the association of intraoperative glucose concentration and variability with AKI after cardiac surgery is scarce ${ }^{7,16-18}$ Furthermore, the results of these studies are somewhat conflicting and remain inconclusive. ${ }^{17,18}$

We hypothesized that intraoperative glucose variability contributes more to postoperative AKI than absolute glucose concentration. Therefore, we conducted a retrospective study to assess the relative importance of average glucose and glucose variability in predicting postoperative AKI in patients undergoing cardiac surgery.

\section{Methods}

\section{Study population}

The study protocol was approved by the Institutional Review Board of Seoul National University Hospital (no. 1801-130-917) on January 31, 2018 and the requirement for written informed consent was waived because of the retrospective nature of this study and lack of patient interaction. All consecutive adult patients (aged $\geq 18 \mathrm{yr}$ ) who underwent cardiac surgery regardless of the use of CPB in our tertiary teaching hospital from November 1, 2006 to December 31, 2016 were retrospectively included in the study. The study dates were chosen based on data from an electronic medical record being readily available. Patients with fewer than six intraoperative glucose measurements, previously diagnosed end-stage renal disease, or renal replacement therapy (RRT) were excluded from the analysis.

\section{Data collection}

Data including patient demographics, comorbidities, medication history, laboratory profiles, and surgery/ anesthesia were retrospectively collected via review of patient electronic medical records. The on-duty physician's notes upon admission for cardiac surgery, intraoperative anesthesia records, and postoperative daily progression notes were available for all patients included in this study. Occurrence of postoperative AKI, in-hospital mortality, 30day mortality, requirement for RRT, and length of stay (LOS) in the intensive care unit (ICU) were retrieved as the outcome variables. Postoperative AKI was defined according to the serum creatinine ( $\mathrm{SCr}$ ) criteria of the Kidney Disease: Improving Global Outcomes (KDIGO) definition for AKI: 1) increase in $\mathrm{SCr}$ by $\geq 0.3 \mathrm{mg} \cdot \mathrm{dl}^{-1}$ within $48 \mathrm{hr}$ or 2) increase in $\mathrm{SCr}$ to $\geq 1.5$ fold the baseline value within seven days. ${ }^{19}$ Serum creatinine was routinely measured in all patients admitted for cardiac surgery in our centre during the study period. The baseline $\mathrm{SCr}$ value was defined as the most recently measured value before surgery. Serial or daily measurement of SCr level after surgery was not protocolized. We obtained the data on 30- 
day mortality from the database of the National Population Registry of the Korean National Statistical Office.

Glycemic control protocol and glucose-related variables

Intraoperative glycemic management was standardized in our institution during the study period. Intraoperative blood glucose measurements were routinely performed by a point-of-care blood gas analyzer (Gem ${ }^{\circledR}$ Premier $^{\mathrm{TM}} 3000$, Instrumentation Laboratory, Bedford, MA, USA) using arterial blood approximately every hour after the induction of anesthesia, and additional measurements were performed when other variables of the blood gas analyzer needed to be assessed. Three to five units of regular insulin were administered intravenously when glucose concentration exceeded $10.0-11.1 \mathrm{mmol} \cdot \mathrm{L}^{-1}$ (for every 1.7-2.8 $\mathrm{mmol} \cdot \mathrm{L}^{-1}$ increment). Glucose concentration was rechecked $30 \mathrm{~min}$ after each insulin injection. When the glucose concentration fell below 3.3-4.4 mmol· $\mathrm{L}^{-1}, 10$ to $20 \mathrm{~mL}$ of $50 \%$ dextrose in water was administered.

Multiple intraoperative blood glucose measurements were averaged into time-weighted average glucose (TWAG) for each patient. Time-weighted average glucose was calculated as the area under the curve divided by the time interval between the first and the last measurement. ${ }^{17,18,20}$ Intraoperative glucose variability was represented by a coefficient of variation (CV), which was calculated as the standard deviation (SD) divided by the mean glucose level. ${ }^{17,18}$ Only patients with a minimum of six intraoperative measurements were included in this study to obtain reliable TWAG and CV values.

Study endpoints and statistical analysis

The primary endpoint was the odds ratio (OR) of perioperative AKI after cardiac surgery according to intraoperative TWAG and CV. The secondary endpoints were the postoperative clinical outcomes, including inhospital mortality, 30-day mortality, requirement for RRT, and ICU LOS. Data of all patients who underwent cardiac surgery during the study period were collected without an $a$ priori sample size calculation. Continuous variables were expressed as mean (SD) or median [interquartile range (IQR)] and compared using the $t$ test, the Mann-Whitney U test, or the Kruskal-Wallis test, where appropriate. Categorical data are presented as numbers with proportions and compared using the $\chi^{2}$ test or the Fisher's exact test.

For the primary outcome comparison, statistical analysis was performed as follows. The TWAG was analyzed as a categorical variable (i.e., $\leq$ or $>7.77 \mathrm{mmol} \cdot \mathrm{L}^{-1}$ ) defining normoglycemia or hyperglycemia, respectively. ${ }^{17}$ An inflection point was located around this cut-off in an exploratory analysis using the restricted cubic spline (data not shown). The CV was analyzed as quartiles. We calculated the OR of the TWAG and the CV strata for postoperative AKI by logistic regression analysis. Body mass index (BMI), left ventricular ejection fraction (LVEF), and duration of CPB were also categorized before the analysis. The BMI was categorized according to the World Health Organization classification (underweight, normal, overweight, and obesity) after identifying the U-shaped relationship between BMI and the risk of AKI in a restricted cubic splines function curve. The LVEF was dichotomized as to whether it was reduced $(<40 \%)$ or not and the duration of CPB was categorized into quartiles. Univariable logistic regression analyses were performed with patient demographics, comorbidities, medication history, laboratory profiles, and surgery/ anesthesia data as well as TWAG and CV. Following the univariable analyses, we performed a multivariable analysis using the potential confounders for which the unadjusted $P$ values were $<0.2$. Thirteen interaction terms were also entered into the multivariable analysis: TWAG$\mathrm{CV}$ and TWAG- or CV- and first intraoperative glucose level, surgery type, preoperative insulin use, deep hypothermic circulatory arrest, occurrence of intraoperative hypoglycemic episodes, and duration of CPB. The stepwise forward method for variable selection was used in the multivariable analysis. ${ }^{21}$ The HosmerLemeshow test was then performed to assess goodness-offit. A restricted cubic splines function curve was generated to evaluate the relationship between $\mathrm{CV}$ and AKI using three knots set at 10, 50, and 90 percentiles.

Additionally, the patients were divided into two groups with regard to $\mathrm{CV}$ using the 75 th percentile as a cut-off to investigate the influence of glucose variability on AKI in patients with very high CV. A propensity score analysis was performed to match the $\mathrm{CV}$ strata using all variables listed in Table 3 including TWAG. In the matching procedure, we used the nearest neighbour-matching method with 1:1 pairing. The caliper was defined as 0.1 SDs of the logit-transformed propensity score. The incidence of postoperative AKI was compared and the ORs were calculated in the matched sample. The same procedure for another propensity score analysis was applied to match the TWAG strata.

We postulated three patterns of glucose variability for their potentially different impact on the occurrence of AKI: negative, positive, or zero slope of the change in the intraoperative glucose level. To explore the association between the slope of glucose measurements and the risk of AKI, we performed a linear regression on each patient in the upper $\mathrm{CV}$ quartile. In the regression, the independent variable was the order of glucose measurements and the 
dependent variable was glucose concentration. Then, we drew a restricted cubic splines function curve showing the relationship between the $\beta$ coefficients and the risk of AKI.

The effect of $\mathrm{CV}$ on postoperative AKI was also assessed by sensitivity analysis, performed separately for the $48 \mathrm{hr}$ - and seven day-window $\mathrm{SCr}$ criteria of the KDIGO. The same procedure for the multivariable analysis described above was applied.

All statistical analyses were carried out using R software (ver. 3.4.3; R Development Core Team, Vienna, Austria). A $P<0.05$ was considered statistically significant.

\section{Results}

Patient characteristics

Of 5,738 patients who underwent cardiac surgery during the study period, 172 patients were excluded because their preoperative $\mathrm{SCr}(n=155)$, LVEF $(n=14)$, or BMI $(n=3)$ values were missing. Of the remaining, 1,968 patients were excluded because of fewer than six intraoperative glucose measurements $(n=1805)$, or end-stage renal disease/RRT $(n=163)$. Finally, 3,598 patients were analyzed (Fig. 1). Patients' characteristics and perioperative data are summarized in Table 1. The median [IQR] number of intraoperative glucose measurements was 8 [7-10]. Glucose concentration was measured every 50.8 (11.9) min on average during the surgery. The median [IQR] length of postoperative hospital stay was 11 [8-19] days. $\mathrm{SCr}$ was measured in all patients on the first postoperative day. On the second and the third postoperative days, $\mathrm{SCr}$

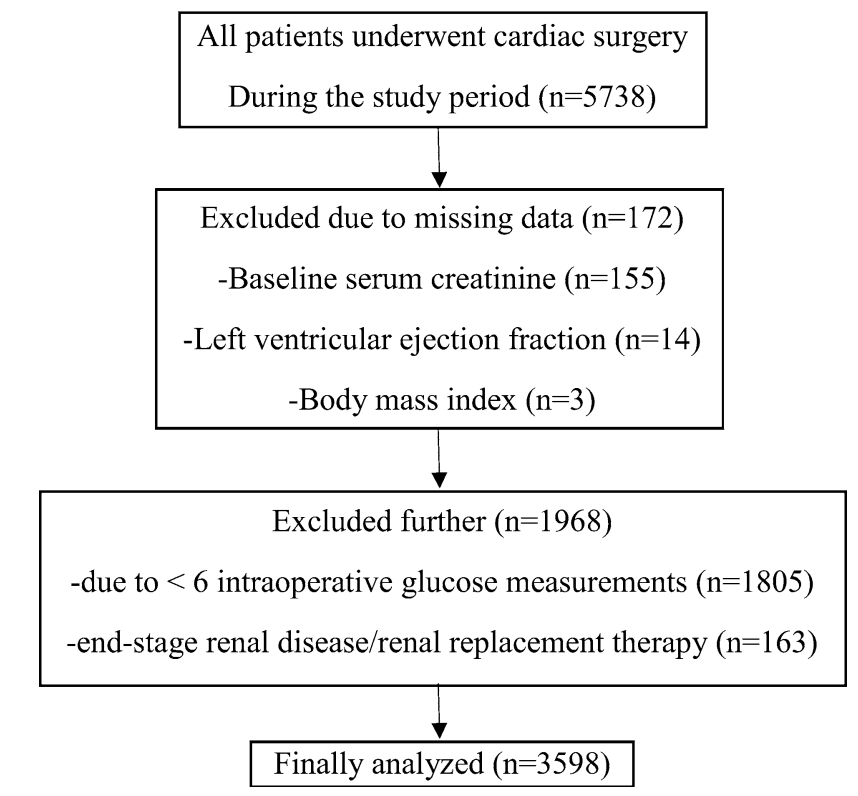

Fig. 1 Flow diagram of the study was measured in 3,488 (97\%) and 3,259 (91\%) patients, respectively. From the fourth to seventh postoperative day, $\mathrm{SCr}$ was measured in $60-76 \%$ of patients on each day, respectively. The median [IQR] number of $\mathrm{SCr}$ measurements during the first seven postoperative days was 6 [5-6], and the numbers according to TWAG and CV strata are shown in Table 1.

Intraoperative glucose and adverse clinical outcomes

The postoperative clinical outcomes according to intraoperative TWAG and CV strata are shown in Table 2. Overall, postoperative AKI developed in 1,552 patients (43.1\%). The incidence of AKI defined by the 48 hr- and seven day-window SCr criteria of the KDIGO was $1,135(31.5 \%)$ and 1,197 (33.3\%), respectively. The incidence of overall AKI was higher in patients with TWAG of $>7.77 \mathrm{mmol} \cdot \mathrm{L}^{-1}$ than in those with TWAG of $\leq 7.77 \mathrm{mmol} \cdot \mathrm{L}^{-1}$. It was also higher in patients in the highest CV quartile than those in the lower three CV quartiles. Similar results were found for in-hospital and 30day mortality, and ICU LOS.

The results of univariable and multivariable logistic regression analysis for postoperative AKI are shown in Table 3, which is the primary outcome of this study. The Hosmer-Lemeshow test revealed that the final model was adequately fitted $(P=0.19)$. Intraoperative $C V$ was an independent risk factor for AKI after cardiac surgery (the highest quartile: OR, 1.38; 95\% confidence interval [CI], 1.09 to $1.75 ; P=0.01)$. Nevertheless, intraoperative TWAG was not retained in the final model. The interaction terms were also not included in the final model. Also, in a sensitivity analysis where the TWAG was forced into the final model, intraoperative TWAG was not significant in the likelihood ratio test $(P=0.43)$; the $\mathrm{OR}$ for AKI of patients with TWAG of $>7.77 \mathrm{mmol} \cdot \mathrm{L}^{-1}$ was 1.05 (95\% CI, 0.89 to $1.24 ; P=0.57$ ) (eTable, available as Electronic Supplementary Material). A restricted cubic splines plot showed an increasing trend of the ORs for postoperative $\mathrm{AKI}$ as intraoperative $\mathrm{CV}$ increased (Fig. 2).

In the propensity score matching, the matched sample was comprised of 792 patients in each CV group. There was no unbalanced confounder with a standardized difference $>0.1$. The standardized difference of each contributor and their distributions are shown in Fig. 3a. In the matched cohort, the incidence of post-cardiac surgery AKI was significantly higher in patients in the fourth quartile of intraoperative $\mathrm{CV}$ compared with those in the lower quartiles $(50.5 \%$ vs $44.8 \%$, respectively; OR, 1.26; 95\% CI, 1.03 to $1.53 ; P=0.02$ ). In the other propensity score analysis for the TWAG groups (Fig. 3b), 693 patients were in each TWAG strata. The incidence of AKI was not significantly different between patients with TWAG $>$ and 


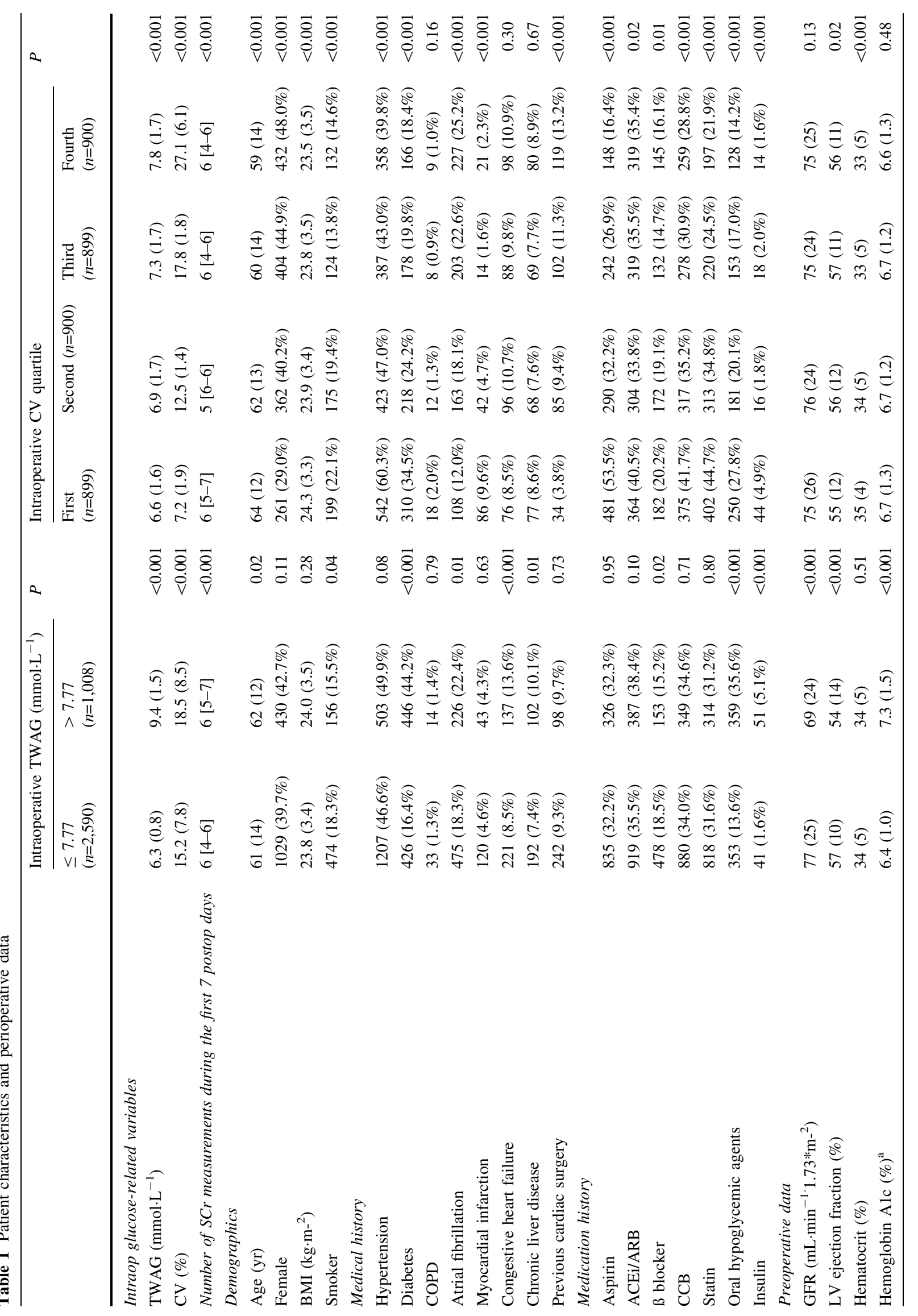




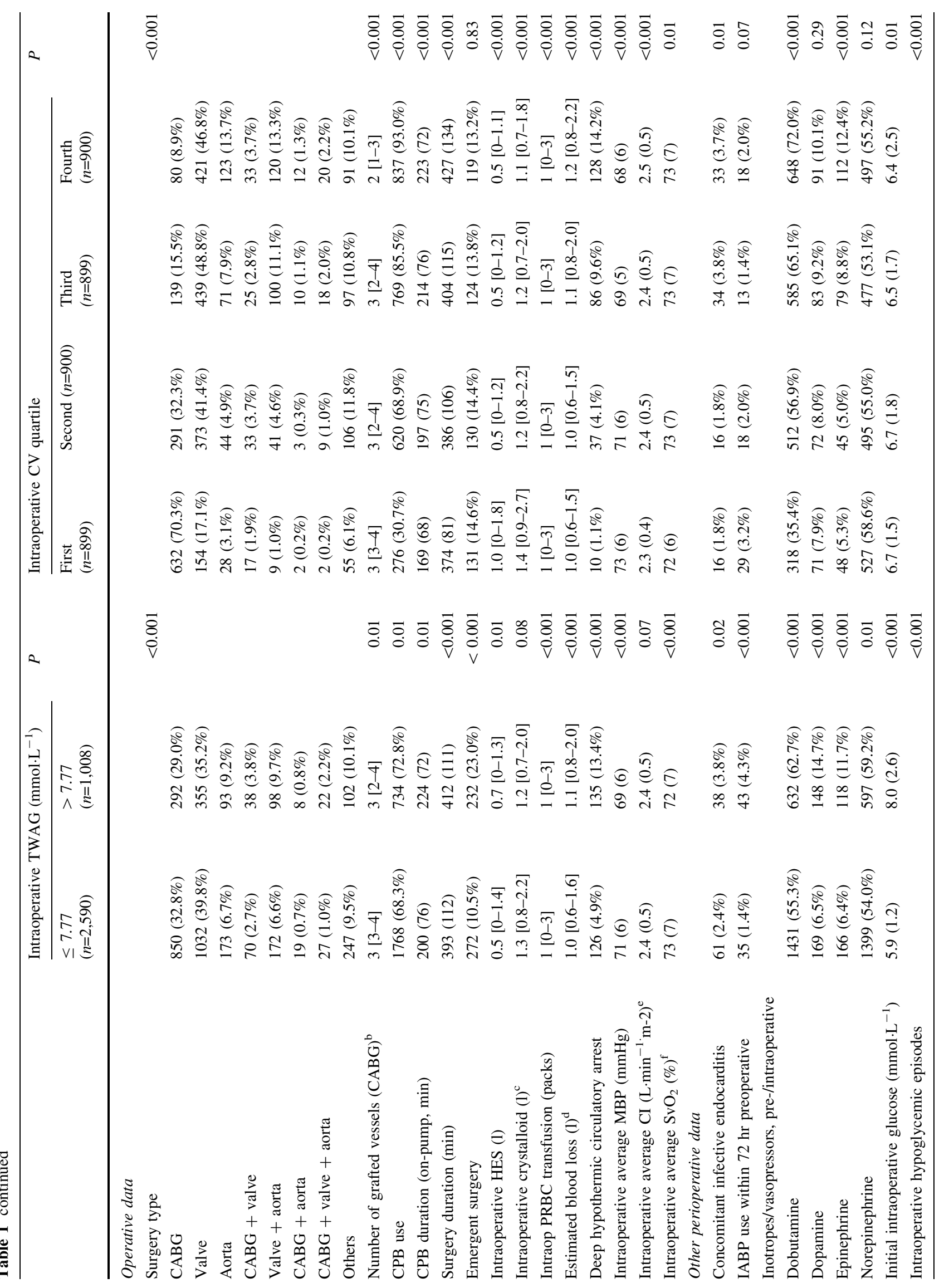




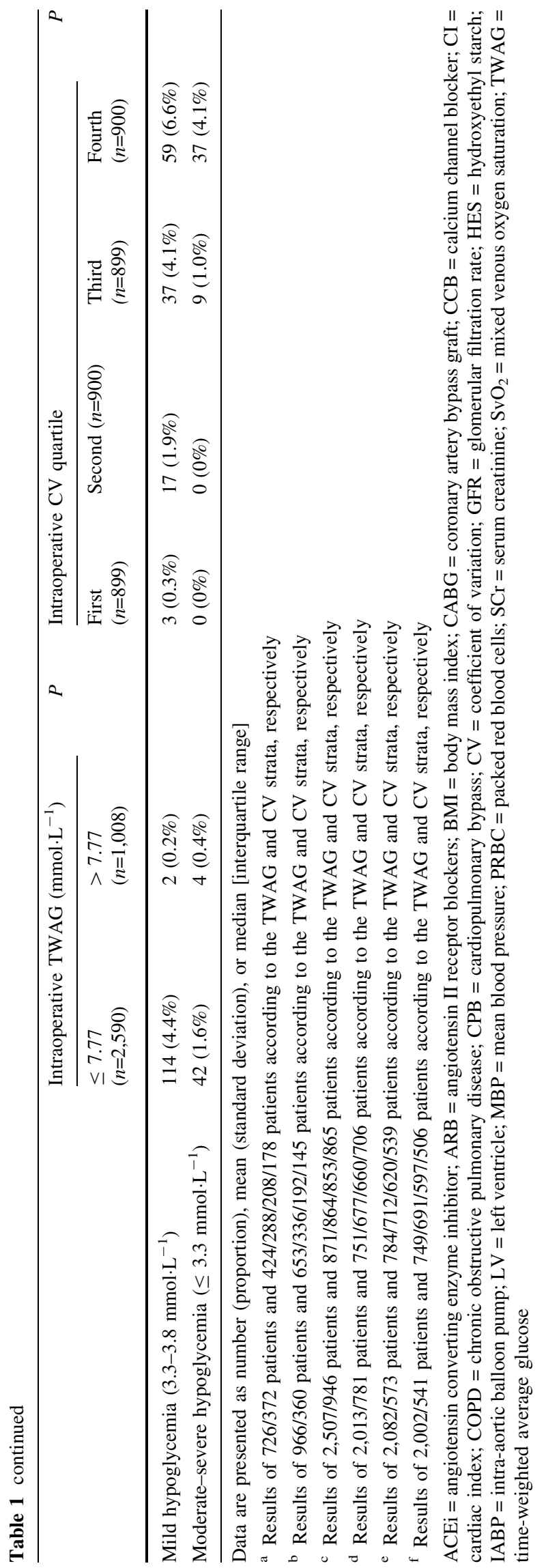

$7.77 \mathrm{mmol} \cdot \mathrm{L}^{-1}$ (45.6 \% vs $44.4 \%$, respectively; OR, 1.05 ; $95 \% \mathrm{CI}, 0.85$ to $1.30, P=0.67)$.

A restricted cubic splines function curve on the association between the slope of glucose measurements and the risk of AKI among patients in the upper $\mathrm{CV}$ quartile is shown in Fig. 4. Patients with a $B$ coefficient near zero had higher risk of AKI than those with a negative or positive $B$ coefficient.

In the sensitivity analysis, intraoperative CV was still a significant risk factor for postoperative AKI defined using the $48 \mathrm{hr} \mathrm{SCr}$ criteria alone (the highest quartile: OR, 1.43; $95 \% \mathrm{CI}, 1.11$ to $1.85 ; P=0.01$ ) while TWAG did not remain in the final model. Similar results were observed when AKI was defined using the seven day-window criteria (the highest quartile: $\mathrm{OR}, 1.51 ; 95 \% \mathrm{CI}, 1.17$ to $1.94 ; P=$ $0.01)$.

We additionally examined 1,805 patients who were excluded from this study because of insufficient number of glucose measurements. The median [IQR] number of intraoperative glucose measurements was 4 [4-5]. They had lower incidence of hypertension (41.3\%), atrial fibrillation (16.5\%), and congestive heart failure $(6.8 \%)$, and shorter median [IQR] duration of surgery (330 [260405] min). The incidence of postoperative AKI (31.5\%) was lower than that of the patients included in this study.

\section{Discussion}

Our study demonstrated that increased intraoperative glucose variability, defined as the $\mathrm{CV}$ of glucose measured during cardiac surgery, was an independent risk factor for postoperative AKI defined by the SCr-based criteria of the KDIGO definition (the urine output criteria was not used). Patients with an increased intraoperative $\mathrm{CV}$ (the highest quartile) had a higher risk of postoperative AKI than those with a lower CV, while TWAG did not remain in the multivariable model. Similar results were found for intraoperative $\mathrm{CV}$ and TWAG in the matched cohorts. Intraoperative $\mathrm{CV}$ also significantly predicted postoperative AKI defined by the $48 \mathrm{hr}$ - or seven daywindow SCr criteria of the KDIGO.

We showed that intraoperative glucose variability may be a more important risk factor for postoperative AKI than glucose concentration per se in cardiac surgery patients. This is concordant with the results of prior studies in critically ill patients where impaired glucose homeostasis is common.12,13 22,23 In cardiac surgery patients, postoperative glucose variability was associated with a composite of adverse outcome after coronary artery bypass grafting, ${ }^{24}$ but not after valve surgery. ${ }^{25}$ Nevertheless, no conclusive link between intraoperative glucose variability and clinical outcomes have been found. ${ }^{17,18}$ In former 
Table 2 Postoperative outcomes according to strata of intraoperative time-weighted average glucose and coefficient of variation

\begin{tabular}{|c|c|c|c|c|c|c|c|c|}
\hline & \multicolumn{2}{|c|}{$\begin{array}{l}\text { Intraoperative TWAG } \\
\left(\mathrm{mmol} \cdot \mathrm{L}^{-1}\right)\end{array}$} & \multirow[t]{2}{*}{$P$} & \multicolumn{4}{|c|}{ Intraoperative $\mathrm{CV}$ quartile } & \multirow[t]{2}{*}{$P$} \\
\hline & $\begin{array}{l}\leq 7.77 \\
(n=2590)\end{array}$ & $\begin{array}{l}>7.77 \\
(n=1008)\end{array}$ & & $\begin{array}{l}\text { First } \\
(n=899)\end{array}$ & Second $(n=900)$ & $\begin{array}{l}\text { Third } \\
(n=899)\end{array}$ & $\begin{array}{l}\text { Fourth } \\
(n=900)\end{array}$ & \\
\hline Acute kidney injury & $1054(40.7 \%)$ & $498(49.4 \%)$ & $<0.001$ & $298(33.1 \%)$ & $376(41.8 \%)$ & $413(45.9 \%)$ & $465(51.7 \%)$ & $<0.001$ \\
\hline Stage 1 & $699(27.0 \%)$ & $332(32.9 \%)$ & & $181(20.1 \%)$ & $243(27.0 \%)$ & $295(32.8 \%)$ & $312(34.7 \%)$ & \\
\hline Stage 2 & $229(8.8 \%)$ & $110(10.9 \%)$ & & $61(6.8 \%)$ & $86(9.6 \%)$ & $84(9.3 \%)$ & $108(12.0 \%)$ & \\
\hline Stage 3 & $126(4.9 \%)$ & $56(5.6 \%)$ & & $56(6.2 \%)$ & $47(5.2 \%)$ & $34(3.8 \%)$ & $45(5.0 \%)$ & \\
\hline In-hospital mortality & $64(2.5 \%)$ & $49(4.9 \%)$ & $<0.001$ & $22(2.4 \%)$ & $23(2.6 \%)$ & $22(2.4 \%)$ & $46(5.1 \%)$ & $<0.001$ \\
\hline 30-day mortality & $78 / 2156(3.6 \%)$ & $44 / 889(4.9 \%)$ & 0.09 & $42 / 759(5.5 \%)$ & $17 / 747(2.3 \%)$ & $28 / 754(3.7 \%)$ & $35 / 785(4.5 \%)$ & 0.01 \\
\hline Renal replacement therapy & $122(4.7 \%)$ & $60(6.0 \%)$ & 0.13 & $41(4.6 \%)$ & $36(4.0 \%)$ & $47(5.2 \%)$ & $58(6.4 \%)$ & 0.10 \\
\hline Length of ICU stay (days) & $2[1-4]$ & $3[2-6]$ & $<0.001$ & $2[1-4]$ & 2 [1-4] & 3 [2-5] & 3 [2-6] & $<0.001$ \\
\hline
\end{tabular}

Data are expressed as $n(\%)$ or median [interquartile range]. $\mathrm{ICU}=$ intensive care unit; $\mathrm{CV}=$ coefficient of variation; TWAG $=$ time-weighted average glucose

studies, the incidence of acute renal morbidities was less than $5 \%(1.9 \%$ and $4.7 \%),{ }^{17,18}$ because they used old definitions of renal morbidity, such as renal failure risk models $^{18}$ or definition by urine output without $\mathrm{SCr}$ values. ${ }^{17}$ Furthermore, the results were inconsistent across the studies. Therefore, these studies may have underestimated or misinterpreted the significance of intraoperative $\mathrm{CV}$ and may not represent true association between glucose control and AKI. In this study, we used the current KDIGO criteria for diagnosis of AKI after cardiac surgery; the incidence of AKI was comparable to recent studies performed in cardiac surgery patients. ${ }^{1,26-28}$

Hyperglycemia has been considered an important factor in the development of postoperative renal dysfunction. ${ }^{18}$ On the other hand, tight perioperative glucose control is known to reduce renal impairment in critically ill patients $^{8-10}$ and in cardiac surgery patients. ${ }^{7}$ Poor glucose control induces renal impairment by increasing oxidative stress, $^{29}$ the inflammatory response, ${ }^{30}$ and endothelial dysfunction. $^{31}$ Glucose homeostasis is frequently disturbed during cardiac surgery by stress-induced hyperglycemia and/or excessive use of glucose-containing cardioplegic solution. ${ }^{15}$ In this context, several studies have reported the association of intraoperative glucose control and AKI in cardiac surgery patients. ${ }^{7,17,18}$ Nevertheless, in this study, TWAG was not a significant risk factor for AKI after cardiac surgery. Although TWAG has the advantage of eliminating bias originating from irregular sample intervals, ${ }^{20}$ it may mask extreme values. ${ }^{32}$ Thus, TWAG may not reflect actual toxic effects of hyperglycemia that may be caused by extreme values. Different cut-offs for categorizing TWAG may also cause different results. ${ }^{17,18}$
Consistent with the results of our study, some investigators argue that glucose variability is a stronger factor than glucose concentration for predicting adverse outcomes. $^{13,20}$ One explanation involves the issue of whether tightly controlled glucose concentration within a narrow range affects glucose variability. Most studies comparing tight glucose control protocols $v s$ a control arm reported that the controlled glucose concentration was important for patient outcomes. ${ }^{7-10}$ Nevertheless, the mechanisms by which glucose variability affects the development of AKI and patient mortality remains unclear. Plausible candidates are suggested by the findings of in vitro studies. ${ }^{33,34}$ Risso et al. reported that alternating euglycemia and hyperglycemia increases the rate of apoptosis. ${ }^{33}$ Using the same method, it was shown that intermittent hyperglycemia enhanced oxidative stress. $^{34}$ In a case-control study conducted in human subjects, acute glucose swing activated oxidative stress, whereas no relationship was observed between sustained hyperglycemia and activation of oxidative stress. ${ }^{35}$ In this study, the term for the interaction between CV and TWAG was not retained in the final model. Nonetheless, further studies on whether glucose variability stratified by mean glucose predicts outcome differently or whether the reducing intraoperative glucose variability improves outcome should follow.

Preoperative high or low glucose levels may present patients with increased glucose variability through a relatively rapid glycemic response (and management) during surgery. The interaction between preoperative glycemic status and intraoperative glucose variability can also be assumed. Although the interaction term of $\mathrm{CV}$ and initial intraoperative glucose level were not kept in our 
Table 3 Logistic regression for acute kidney injury after cardiac surgery

\begin{tabular}{|c|c|c|c|c|}
\hline & \multicolumn{2}{|l|}{ Unadjusted model } & \multicolumn{2}{|l|}{ Adjusted model } \\
\hline & OR $(95 \% \mathrm{CI})$ & $P$ & OR $(95 \% \mathrm{CI})$ & $P$ \\
\hline TWAG & & $<0.001$ & & \\
\hline$\leq 7.77 \mathrm{mmol} \cdot \mathrm{L}^{-1}$ & 1.00 (Reference) & & & \\
\hline$>7.77 \mathrm{mmol} \cdot \mathrm{L}^{-1}$ & $1.42(1.23$ to 1.65$)$ & & & \\
\hline \multicolumn{5}{|l|}{ Glucose variability $(\mathrm{CV})$} \\
\hline Quartile 1 & 1.00 (Reference) & & 1.00 (Reference) & \\
\hline Quartile 2 & $1.45(1.19$ to 1.75$)$ & $<0.001$ & 1.19 (0.96 to 1.48$)$ & 0.11 \\
\hline Quartile 3 & 1.71 (1.42 to 2.08$)$ & $<0.001$ & $1.26(1.00$ to 1.58$)$ & 0.05 \\
\hline Quartile 4 & $2.16(1.78$ to 2.61$)$ & $<0.001$ & $1.38(1.09$ to 1.75$)$ & 0.01 \\
\hline No. of SCr measurements during the first 7 postop days & $1.55(1.47$ to 1.64$)$ & $<0.001$ & $1.58(1.48$ to 1.69$)$ & $<0.001$ \\
\hline Age $(y r)$ & 1.019 (1.014 to 1.24$)$ & $<0.001$ & 1.01 (1.01 to 1.02$)$ & $<0.001$ \\
\hline Female & $1.13(0.99$ to 1.30$)$ & 0.07 & & \\
\hline BMI & & 0.41 & & \\
\hline$<18.5 \mathrm{~kg} \cdot \mathrm{m}^{-2}$ & $1.19(0.88$ to 1.61$)$ & & & \\
\hline $18.5-24.9 \mathrm{~kg} \cdot \mathrm{m}^{-2}$ & 1.00 (Reference) & & & \\
\hline $25.0-29.9 \mathrm{~kg} \cdot \mathrm{m}^{-2}$ & 0.97 (0.84 to 1.13$)$ & & & \\
\hline$\geq 30.0 \mathrm{~kg} \cdot \mathrm{m}^{-2}$ & $1.20(0.87$ to 1.67$)$ & & & \\
\hline Smoker & $0.86(0.72$ to 1.03$)$ & 0.09 & & \\
\hline \multicolumn{5}{|l|}{ Medical history } \\
\hline Hypertension & $1.26(1.10$ to 1.44$)$ & 0.01 & 1.17 (0.99 to 1.37$)$ & 0.05 \\
\hline Diabetes & $1.10(0.95$ to 1.29$)$ & 0.21 & & \\
\hline COPD & 1.38 (0.78 to 2.46$)$ & 0.27 & & \\
\hline Atrial fibrillation & 1.58 (1.34 to 1.86$)$ & $<0.001$ & 1.18 (0.98 to 1.42$)$ & 0.08 \\
\hline Myocardial infarction & $1.02(0.74$ to 1.40$)$ & 0.97 & & \\
\hline Congestive heart failure & 1.75 (1.40 to 2.18$)$ & $<0.001$ & & \\
\hline Chronic liver disease & $1.11(0.88$ to 1.42$)$ & 0.38 & & \\
\hline Previous cardiac surgery & 1.65 (1.32 to 2.07$)$ & $<0.001$ & & \\
\hline \multicolumn{5}{|l|}{ Medication history } \\
\hline Aspirin & $0.85(0.74$ to 0.98$)$ & 0.03 & & \\
\hline ACEi/ARB & $1.23(1.07$ to 1.41$)$ & 0.01 & & \\
\hline ß blocker & $1.06(0.89$ to 1.25$)$ & 0.55 & & \\
\hline $\mathrm{CCB}$ & $1.11(0.97$ to 1.28$)$ & 0.14 & & \\
\hline Statin & 0.94 (0.82 to 1.09$)$ & 0.41 & & \\
\hline Insulin & $0.66(0.43$ to 1.03$)$ & 0.06 & $0.69(0.43$ to 1.10$)$ & 0.12 \\
\hline Oral hypoglycemic agents & 1.07 (0.90 to 1.26$)$ & 0.45 & & \\
\hline \multicolumn{5}{|l|}{ Preoperative data } \\
\hline GFR $\left(\mathrm{mL} \cdot \mathrm{min}^{-1} \cdot 1.73 \cdot \mathrm{m}^{-2}\right)$ & 0.998 (0.996 to 1.002$)$ & 0.44 & & \\
\hline LV ejection fraction $<40 \%$ & $1.16(0.94$ to 1.43$)$ & 0.16 & & \\
\hline Hematocrit $(\%)$ & 0.97 (0.95 to 0.98$)$ & $<0.001$ & $0.99(0.97$ to 1.00$)$ & 0.07 \\
\hline \multicolumn{5}{|l|}{ Operative data } \\
\hline Surgery type & & $<0.001$ & & \\
\hline CABG & 1.00 (Reference) & & & \\
\hline Valve & 1.54 (1.31 to 1.82$)$ & & & \\
\hline Aorta & $2.48(1.89$ to 3.25$)$ & & & \\
\hline $\mathrm{CABG}+$ valve & $2.72(1.82$ to 4.07$)$ & & & \\
\hline Valve + aorta & $2.70(2.06$ to 3.54$)$ & & & \\
\hline $\mathrm{CABG}+$ aorta & $2.43(1.13$ to 5.24$)$ & & & \\
\hline $\mathrm{CABG}+$ valve + aorta & $2.60(1.45$ to 4.62$)$ & & & \\
\hline
\end{tabular}


Table 3 continued

\begin{tabular}{|c|c|c|c|c|}
\hline & \multicolumn{2}{|l|}{ Unadjusted model } & \multicolumn{2}{|l|}{ Adjusted model } \\
\hline & OR $(95 \% \mathrm{CI})$ & $P$ & OR $(95 \% \mathrm{CI})$ & $P$ \\
\hline Others & $1.27(0.99$ to 1.33$)$ & & & \\
\hline Duration of CPB & & $<0.001$ & & \\
\hline Quartile 1 & 1.00 (Reference) & & 1.00 (Reference) & \\
\hline Quartile 2 & $1.10(0.90$ to 1.34$)$ & & 1.79 (1.39 to 2.29$)$ & $<0.001$ \\
\hline Quartile 3 & $1.92(1.60$ to 2.31$)$ & & 2.11 (1.65 to 2.70$)$ & $<0.001$ \\
\hline Quartile 4 & 2.85 (2.37 to 3.42$)$ & & 2.11 (1.62 to 2.76$)$ & $<0.001$ \\
\hline Surgery duration (min) & $1.003(1.003$ to 1.004$)$ & $<0.001$ & $1.001(1.000$ to 1.002$)$ & 0.01 \\
\hline Emergent surgery & $1.22(1.01$ to 1.48$)$ & 0.04 & & \\
\hline Intraoperative HES use & $1.45(1.26$ to 1.66$)$ & $<0.001$ & $1.72(1.47$ to 2.02$)$ & $<0.001$ \\
\hline Intraoperative $\mathrm{PRBC}$ transfusion & $1.38(1.21$ to 1.58$)$ & $<0.001$ & & \\
\hline Deep hypothermic circulatory arrest & 2.14 (1.65 to 2.77$)$ & $<0.001$ & $1.32(0.99$ to 1.76$)$ & 0.06 \\
\hline Intraoperative average $\mathrm{MBP}(\mathrm{mmHg})$ & $0.95(0.94$ to 0.96$)$ & $<0.001$ & & \\
\hline \multicolumn{5}{|l|}{ Other perioperative data } \\
\hline Concomitant infective endocarditis & $1.15(0.77$ to 1.71$)$ & 0.50 & & \\
\hline IABP use within $72 \mathrm{~h}$ preoperative & $1.40(0.89$ to 2.19$)$ & 0.14 & & \\
\hline \multicolumn{5}{|l|}{ Inotropes/vasopressors, pre-/intraoperative } \\
\hline Dobutamine & $1.90(1.66$ to 2.18$)$ & $<0.001$ & $1.27(1.07$ to 1.50$)$ & 0.01 \\
\hline Dopamine & $1.91(1.51$ to 2.41$)$ & $<0.001$ & $1.22(0.95$ to 1.58$)$ & 0.12 \\
\hline Epinephrine & $2.02(1.58$ to 2.58$)$ & $<0.001$ & & \\
\hline Norepinephrine & $1.20(1.05$ to 1.37$)$ & 0.01 & & \\
\hline Initial intraoperative glucose $\left(\mathrm{mmol} \cdot \mathrm{L}^{-1}\right)$ & 1.03 (1.00 to 1.07$)$ & 0.06 & & \\
\hline Intraoperative hypoglycemic episode & & 0.07 & & \\
\hline Mild hypoglycemia $\left(3.3-3.8 \mathrm{mmol} \cdot \mathrm{L}^{-1}\right)$ & $1.49(1.03$ to 2.15$)$ & & & \\
\hline Moderate-severe hypoglycemia $\left(\leq 3.3 \mathrm{mmol} \cdot \mathrm{L}^{-1}\right)$ & $1.34(0.75$ to 2.40$)$ & & & \\
\hline
\end{tabular}

$\mathrm{ACEi}$, = angiotensin converting enzyme inhibitor; $\mathrm{ARB}=$ angiotensin II receptor blockers; $\mathrm{BMI}=$ body mass index; CABG = coronary artery bypass graft; $\mathrm{CCB}=$ calcium channel blocker; $\mathrm{CI}=$ confidence interval; $\mathrm{COPD}=$ chronic obstructive pulmonary disease; $\mathrm{CPB}=$ cardiopulmonary bypass; $\mathrm{CV}=$ coefficient of variation; $\mathrm{GFR}=$ glomerular filtration rate; HES = hydroxyethyl starch; $\mathrm{LV}=$ left ventricle; $\mathrm{MBP}=$ mean blood pressure; $\mathrm{OR}=$ odds ratio; $\mathrm{PRBC}=$ packed red blood cells; $\mathrm{SCr}=$ serum creatinine; $\mathrm{TWAG}=$ time-weighted average glucose

multivariable model, they were still required to investigate this issue further. In our exploratory analysis of the slope of glucose measurements, we note that patients with a fluctuation of glucose concentration throughout the surgery (i.e., a "zero slope") had higher risk of AKI than those with an increasing or decreasing trend of glucose concentration among the patients with high glucose variability (Fig. 4). In addition, the risk of AKI seemed to be higher in patients with a positive slope compared with patients with a negative slope. Considering that there was no hypoglycemic patient with $\mathrm{TWAG}<3.8 \mathrm{mmol} \cdot \mathrm{L}^{-1}$ in our data, patients who were initially normoglycemic then became hyperglycemic may have a higher risk of AKI than those who were initially hyperglycemic and became normoglycemic.

There are several limitations to this study. First, this analysis was based on data from a retrospective review of electronic medical records. Although various potential confounders were adjusted for, the bias inherent to retrospective studies may have affected the results. Second, we used intermittent doses of regular insulin to control intraoperative hyperglycemia. Compared with continuous infusion of insulin, intermittent bolus injection of insulin may increase glucose variability. Moreover, the amount of insulin administered intraoperatively was not analyzed in this study. Third, measurements of postoperative $\mathrm{SCr}$ and intraoperative glucose were not standardized. Patients with more comorbidities tend to be tested more frequently, which may have biased the $\mathrm{CV}$ and/or the observed incidence of postoperative AKI in this study. Fourth, the effect of immediate postoperative glucose control was not analyzed in the study. Given the potential significant effect of the postoperative mean or variability of glucose, ${ }^{17,24,36}$ 


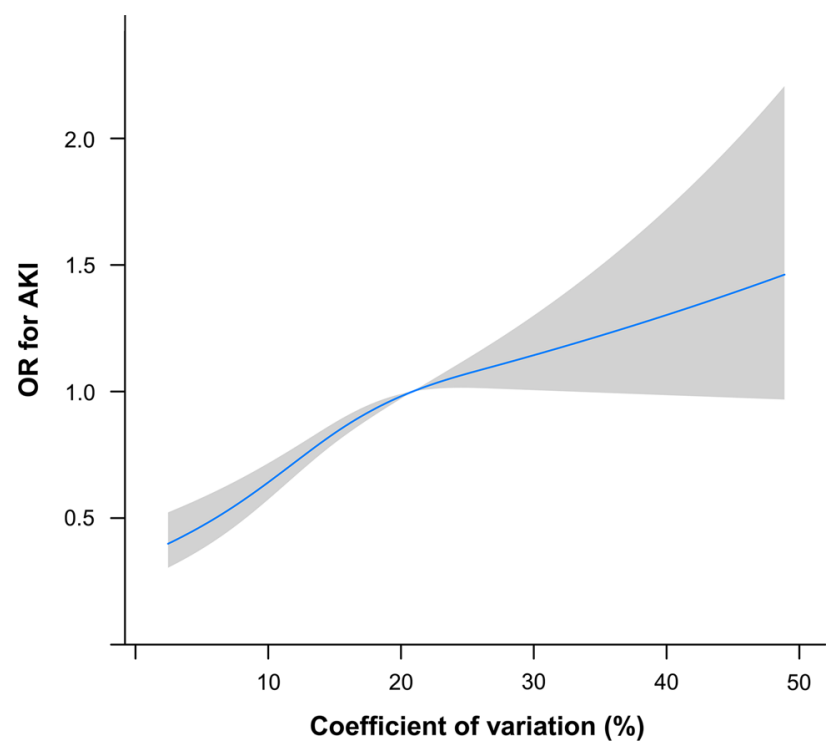

Fig. 2 Restricted cubic splines function curve depicting the increase in the odds ratios for acute kidney injury after cardiac surgery according to the increase in the coefficient of variation of intraoperative glucose. The odds ratios were referenced to the $75^{\text {th }}$ percentile of the coefficient of variation. AKI = acute kidney injury; $\mathrm{OR}=$ odds ratio

adjustment for postoperative glucose control is warranted. Fifth, we did not use the urine output criteria for AKI diagnosis because accurate hourly urine output data were not available. Thus, the incidence of AKI may have been underestimated. Sixth, the impact of glucose concentration and variability may be different in patients with diabetes

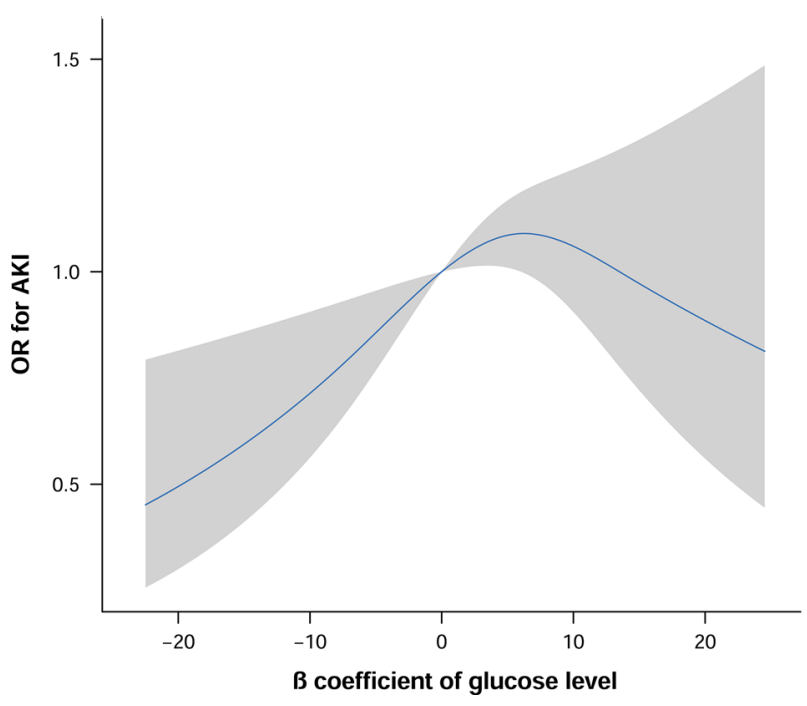

Fig. 4 Restricted cubic splines function curves depicting the odds ratios for acute kidney injury after cardiac surgery according to the change in $B$ coefficient of intraoperative glucose measurements of patients in the fourth quartile of the coefficient of variation. The odds ratios were referenced to the $\beta$ coefficient of zero. AKI = acute kidney injury; OR = odds ratio

compared with non-diabetic patients. Also, the type of diabetes may affect the glucose derangement. Although we took the history of diabetes into consideration, further studies focusing on diabetic patients are necessary.

In conclusion, intraoperative $\mathrm{CV}$ may be an independent risk factor for postoperative AKI after cardiac surgery. Increased glucose variability is related with the increased (a)

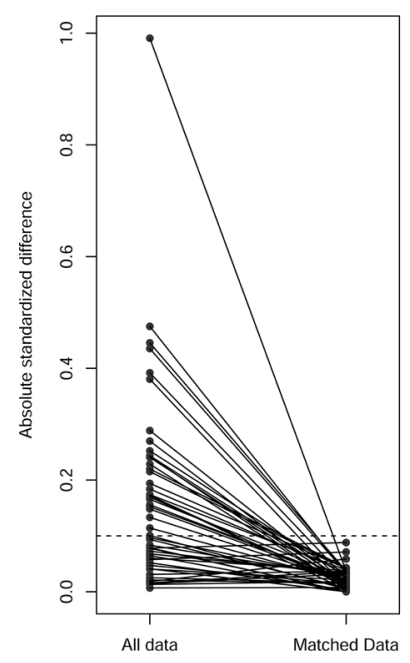

Before matching
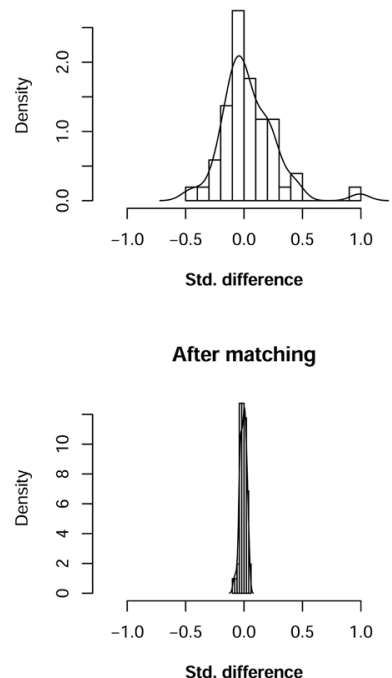

(b)

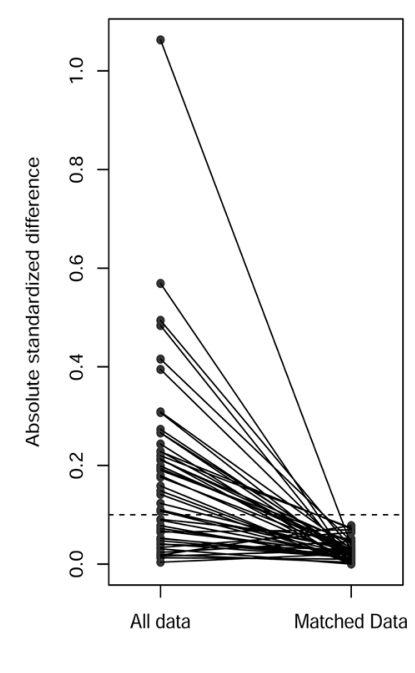

Before matching

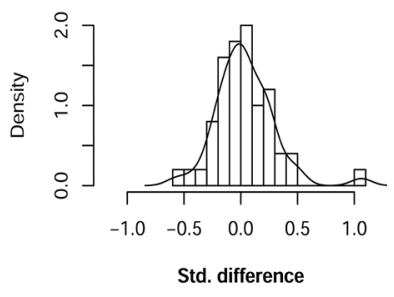

After matching

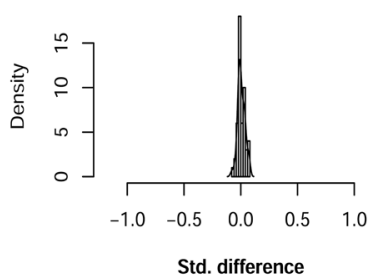

Fig. 3 Line plots for (a) the time-weighted average glucose and (b) the coefficient of variation showing differences in matched variables (left panel) and histograms and densitograms depicting standardized differences before and after matching (right panels) 
risk of postoperative AKI, while the average glucose concentration is not.

\section{Conflict of interest None declared.}

Editorial responsibility This submission was handled by Dr. Hilary P. Grocott, Editor-in-Chief, Canadian Journal of Anesthesia.

\begin{abstract}
Author contributions Karam Nam contributed to the study design, data collection, analysis, and writing the paper. Yunseok Jeon contributed to the study design, writing the paper, and revising the paper. Won Ho Kim contributed to the study design, data analysis, and revising the paper. Dhong Eun Jung contributed to data collection, writing the paper, and revising the paper. Seok Min Kwon, Pyoyoon Kang and Youn Joung Cho contributed to data collection, data analysis, and revising the paper. Tae Kyong Kim contributed to study design/planning, data collection, data analysis, and revising the paper.
\end{abstract}

Funding None declared.

\section{References}

1. Hobson CE, Yavas S, Segal MS, et al. Acute kidney injury is associated with increased long-term mortality after cardiothoracic surgery. Circulation 2009; 119: 2444-53.

2. Chertow GM, Levy EM, Hammermeister KE, Grover F, Daley J. Independent association between acute renal failure and mortality following cardiac surgery. Am J Med 1998; 104: 343-8.

3. Bonventre $J V, Z u k A$. Ischemic acute renal failure: an inflammatory disease? Kidney Int 2004; 66: 480-5.

4. Scrascia G, Guida P, Rotunno C, de Luca Tupputi Schinosa L, Paparella $D$. Anti-inflammatory strategies to reduce acute kidney injury in cardiac surgery patients: a meta-analysis of randomized controlled trials. Artif Organs 2014; 38: 101-12.

5. Pathi VL, Morrison J, MacPhaden A, Martin W, McQuiston AM, Wheatley DJ. Alterations in renal microcirculation during cardiopulmonary bypass. Ann Thorac Surg 1998; 65: 993-8.

6. Molitoris BA, Sandoval R, Sutton TA. Endothelial injury and dysfunction in ischemic acute renal failure. Crit Care Med 2002; 30: S235-40.

7. Lecomte P, Van Vlem B, Coddens J, et al. Tight perioperative glucose control is associated with a reduction in renal impairment and renal failure in non-diabetic cardiac surgical patients. Crit Care 2008; 12: R154.

8. Schetz, M, Vanhorebeek I, Wouters PJ, Wilmer A, Van den Berghe $G$. Tight blood glucose control is renoprotective in critically ill patients. J Am Soc Nephrol 2008; 19: 571-8.

9. Van den Berghe $G$, Wilmer A, Hermans $G$, et al. Intensive insulin therapy in the medical ICU. N Engl J Med 2006; 354: 449-61.

10. Van den Berghe $G$, Wouters $P$, Weekers $F$, et al. Intensive insulin therapy in critically ill patients. N Engl J Med 2001; 345: 135967.

11. Frontoni S, Di Bartolo P, Avogaro A, Bosi E, Paolisso G, Ceriello A. Glucose variability: an emerging target for the treatment of diabetes mellitus. Diabetes Res Clin Pract 2013; 102: 86-95.

12. Hermanides J, Vriesendorp TM, Bosman RJ, Zandstra DF, Hoekstra JB, Devries JH. Glucose variability is associated with intensive care unit mortality. Crit Care Med 2010; 38: 838-42.
13. Egi M, Bellomo R, Stachowski E, French CJ, Hart G. Variability of blood glucose concentration and short-term mortality in critically ill patients. Anesthesiology 2006; 105: 244-52.

14. Ali NA, O'Brien JM Jr, Dungan K, et al. Glucose variability and mortality in patients with sepsis. Crit Care Med 2008; 36: 231621.

15. Anderson RE, Brismar $K$, Barr $G$, Ivert $T$. Effects of cardiopulmonary bypass on glucose homeostasis after coronary artery bypass surgery. Eur J Cardiothorac Surg 2005; 28: 425-30.

16. Ouattara A, Lecomte $P$, Le Manach $Y$, et al. Poor intraoperative blood glucose control is associated with a worsened hospital outcome after cardiac surgery in diabetic patients. Anesthesiology 2005; 103: 687-94.

17. Duncan AE, Abd-Elsayed A, Maheshwari A, Xu M, Soltesz E, Koch $C G$. Role of intraoperative and postoperative blood glucose concentrations in predicting outcomes after cardiac surgery. Anesthesiology 2010; 112: 860-71.

18. Song JW, Shim JK, Yoo KJ, Oh SY, Kwak YL. Impact of intraoperative hyperglycaemia on renal dysfunction after offpump coronary artery bypass. Interact Cardiovasc Thorac Surg 2013; 17: 473-8.

19. Kidney Disease: Improving Global Outcomes (KDIGO) Acute Kidney Injury Work Group. KDIGO clinical practice guideline for acute kidney injury. Kidney Int Suppl 2012; 2: 1-138.

20. Yoo $S$, Lee HJ, Lee $H$, Ryu $H G$. Association between perioperative hyperglycemia or glucose variability and postoperative acute kidney injury after liver transplantation: a retrospective observational study. Anesth Analg 2017; 124: 3541.

21. Thorpe KE. How to construct regression models for observational studies (and how NOT to do it!). Can J Anesth 2017; 64: 461-70.

22. Bagshaw SM, Bellomo R, Jacka MJ, et al. The impact of early hypoglycemia and blood glucose variability on outcome in critical illness. Crit Care 2009; 13: R91.

23. Krinsley JS. Glycemic variability: a strong independent predictor of mortality in critically ill patients. Crit Care Med 2008; 36: 3008-13.

24. Subramaniam B, Lerner A, Novack $V$, et al. Increased glycemic variability in patients with elevated preoperative HbA1C predicts adverse outcomes following coronary artery bypass grafting surgery. Anesth Analg 2014; 118: 277-87.

25. Bardia A, Khabbaz K, Mueller A, et al. The association between preoperative hemoglobin A1C and postoperative glycemic variability on 30-day major adverse outcomes following isolated cardiac valvular surgery. Anesth Analg 2017; 124: 16-22.

26. Bastin AJ, Ostermann M, Slack AJ, Diller GP, Finney SJ, Evans $T W$. Acute kidney injury after cardiac surgery according to Risk/ Injury/Failure/Loss/End-stage, Acute Kidney Injury Network, and Kidney Disease: Improving Global Outcomes classifications. J Crit Care 2013; 28: 389-96.

27. Haase M, Bellomo R, Matalanis $G$, Calzavacca P, Dragun D, Haase-Fielitz A. A comparison of the RIFLE and Acute Kidney Injury Network classifications for cardiac surgery-associated acute kidney injury: a prospective cohort study. J Thorac Cardiovasc Surg 2009; 138: 1370-6.

28. Machado MN, Miranda RC, Takakura IT, et al. Acute kidney injury after on-pump coronary artery bypass graft surgery. Arq Bras Cardiol 2009; 93: 247-52.

29. Hirose $R, X u F$, Dang $K$, et al. Transient hyperglycemia affects the extent of ischemia-reperfusion-induced renal injury in rats. Anesthesiology 2008; 108: 402-14.

30. Esposito $K$, Nappo $F$, Marfella $R$, et al. Inflammatory cytokine concentrations are acutely increased by hyperglycemia in humans: role of oxidative stress. Circulation 2002; 106: 2067-72.

31. Ellger B, Debaveye Y, Vanhorebeek I, et al. Survival benefits of intensive insulin therapy in critical illness: impact of maintaining 
normoglycemia versus glycemia-independent actions of insulin. Diabetes 2006; 55: 1096-105.

32. Badawi O, Yeung SY, Rosenfeld BA. Evaluation of glycemic control metrics for intensive care unit populations. Am J Med Qual 2009; 24: 310-20.

33. Risso A, Mercuri F, Quagliaro L, Damante $G$, Ceriello A. Intermittent high glucose enhances apoptosis in human umbilical vein endothelial cells in culture. Am J Physiol Endocrinol Metab 2001; 281: E924-30.

34. Quagliaro L, Piconi L, Assaloni R, Martinelli L, Motz E, Ceriello $A$. Intermittent high glucose enhances apoptosis related to oxidative stress in human umbilical vein endothelial cells: the role of protein kinase $\mathrm{C}$ and $\mathrm{NAD}(\mathrm{P}) \mathrm{H}$-oxidase activation. Diabetes 2003; 52: 2795-804.

35. Monnier L, Mas E, Ginet $C$, et al. Activation of oxidative stress by acute glucose fluctuations compared with sustained chronic hyperglycemia in patients with type 2 diabetes. JAMA 2006; 295 : 1681-7.

36. Bansal B, Carvalho P, Mehta $Y$, et al. Prognostic significance of glycemic variability after cardiac surgery. J Diabetes Complications 2016; 30: 613-7.

Publisher's Note Springer Nature remains neutral with regard to jurisdictional claims in published maps and institutional affiliations. 